\title{
Efektivitas Peran Gembala Jemaat dalam Pertumbuhan Gereja
}

\author{
Yulia Santoso \\ Sekolah Tinggi Alkitab Jember, Jember, Jawa Timur, Indonesia \\ yuliasantoso10@yahoo.com
}

\begin{abstract}
This article is a research result of the role of the pastor's effectiveness in church growth. As for the object examined in this thesis in accordance with the context of the pastor, "about the effectiveness of the pastor who is very influential in the growth of the church in accordance with the ministry and responsibilities as a shepherd." Although there are many strong and hard obstacles that can cause occurrence obstacles in growth, seem slow and stagnant, but the pastoral task must continue to be done and the pastor needs to increase its effectiveness by finding more effective methods so as to find a better way of pastoral care. The effectiveness of the pastor's ministry is very important to be done seriously in order to obtain success in carrying out this ministry from God.
\end{abstract}

Keywords: church growth; effectiveness of pastor; the pastor of the church; the role of the pastor

\begin{abstract}
Abstrak
Artikel ini adalah sebuah hasil penelitian dari peranan efektivitas gembala jemaat terhadap pertumbuhan gereja. Adapun yang menjadi objek yang diteliti dalam tesis ini sesuai dengan konteksnya yaitu gembala jemaat, " tentang efektivitas gembala jemaat yang sangat berpengaruh terjadinya pertumbuhan gereja sesuai dengan pelayanan dan tanggungjawabnya sebagai gembala." Walaupun ada banyak hambatan-hambatan yang kuat dan keras yang dapat menyebabkan terjadinya hambatan dalam pertumbuhan, terkesan lambat dan stagnan, namun tugas penggembalaan harus tetap dilakukan dan gembala jemaat perlu meningkatkan efektivitasnya dengan mencari metode yang lebih efektif sehingga menemukan cara yang lebih baik dalam tugas penggembalaan. Efektivitas pelayanan gembala ini sangat penting dilakukan dengan sungguhsungguh agar memperoleh keberhasilan dalam melaksanakan tugas pelayanan dari Tuhan ini.
\end{abstract}

Kata Kunci: efektivitas gembala; gembala jemaat; peran gembala; pertumbuhan gereja

\section{PENDAHULUAN}

Penggembalaan merupakan pekerjaan yang mulia dari Tuhan, yang harus dikerjakan dalam kasih kepada jemaat oleh seorang gembala di dalam tugas pelayanannya. Tugas dalam penggembalaan merupakan pekerjaan yang harus ditangani secara serius, karena pada masalah ini tidak sama dengan masa lalu di dalam menangani pelayanan penggembalaan. Sebab, zaman telah berubah dan pelayanan penggembalaan perlu ditingkatkan efaktifitasnya. Sehubungan dengan pelayanan Yesus sebagai gembala yang baik menurut kesaksian penulis-penulis Injil, khususnya Injil Matius: adalah Penuh belas kasihan. Dalam Matius 28:19-20, Amanat Agung Tuhan Yesus Kristus, orang-orang 
percaya bukan hanya sampai "dimenangkan bagi Kristus" saja sudah cukup, tetapi mereka harus "diajar" untuk melakukan kehendak Allah. ${ }^{1}$

Pengertian Gembala yang baik secara global. Gembala yang baik adalah Seorang pemimpin atau panutan bagi domba-domba, anak-anak, orang-orang yang ada di sekitarnya, dan harus menjadi contoh yang baik, bukan hanya mengajarkan tetapi mengarahkan kawananya ke jalan yang benar. Gembala yang baik akan bertanggung jawab terhadap kepemimpinannya menjadi seorang gembala, bukan hanya dalam konteks kinerjanya yang bagus tetapi juga perbuatannya. Pengertian Gembala dalam Alkitab dapat dilihat pada Yohanes 10:11-13. Pada ayat 11 Yesus berkata, "Akulah gembala yang baik. Gembala yang baik memberikan nyawanya bagi domba-dombanya." Artinya, gembala adalah seorang yang merelakan sebagian hidupnya untuk domba-dombanya, bahkan bukan sebagian saja namun seluruh hidupnya. Hal yang serupa juga disebutkan pada Mazmur 23:1-6, Gembala yang baik selalu memberikan yang terbaik bagi domba-dombanya, memberikan bimbingan dan arahan kemana domba-dombanya berjalan.

Terkait dengan tugas gembala sidang yang efektif, maka istilah efektif dapat mengandung arti manjur dan mujarab; membawa hasil yang sebesar-besarnya atau berhasil guna. Pelayanan kepada umat dapat diekspresikan dan didemontrasikan melalui beberapa cara. Gembala bertanggung jawab langsung kepada Allah untuk: Melayani kebutuhankebutuhan mereka pribadi, memiliki rasa kepedulian yang hangat terhadap umat yang dipercayakan Allah kepadanya (1 Pet. 5:1-4). Memperlengkapi dan melatih dombadombanya untuk melakukan pelayanan terhadap sesama dibawa bimbingan dan superviser dari gembala (Ef. 4:11-12; 2 Tim. 2:2). Gembala harus melihat dirinya sebagai pelatih bagi orang-orang percaya. ${ }^{2}$ Dalam hal ini ada beberapa hubungan gembala yang efektif dalam pelayanan penggembalaan yaitu:

\section{Hubungan Gembala yang Baik dan Pemelihara Domba}

Dimulai dengan Petrus, para gembala jemaat diperintahkan untuk menunjukkan kasih agape kepada Tuhan. Petrus mengetahui dengan tepat bahwa kasih sejati itu ada pada Allah. Satu-satunya pengetahuannya yang benar tentang kasih itu dari penampakan kehidupan Yesus. Dalam kematian-Nya, Yesus memberikan makna kasih yang telah mengorbankan diri-Nya bagi gerejaNya. Kasih kepada Yesus gembala yang baik mengharuskan domba melakukan perintah-perintah-Nya. ${ }^{3}$ Artur Pink menyatakan:

\footnotetext{
${ }^{1}$ Susanto Dwiraharjo, "Kajian Eksegetikal Amanat Agung Menurut Matius 28 : 18-20," Jurnal Teologi Gracia Deo 1, no. 2 (2019): 56-73, http://sttbaptisjkt.ac.id/e-journal/index.php/graciadeo.

${ }^{2}$ L. Anthony, Pelayanan Pastoral (Yokyakarta: STII, Diktat), 21

3 Jerry C. Worfford, Kepemimpinan Kristen yang Mengubahkan, (Yogyakarta: Yayasan ANDI, 1999), 133
} 
Iman adalah akar di mana ketaatan adalah bunga dan buah yang indah. Suatu ketaatan yang penuh dengan suka cita memikul salib dan rasa malu-dengan demikian janji tertinggi Injil digenapi...Jika kasih kepada Juru Selamat akan memimpin kita untuk taat kepada Firman-Nya tidak berlambat-lambat, ketaatan yang jelas dan tidak bimbang - memimpin kita untuk mengatakan dalam roh yang sepenuhnya menundukkan diri dan mengorbankan diri, 'kehendak-Mu, bukan kehendakku. ${ }^{4}$

Yesus telah menyatakan persahabatan dengan para pengikut-Nya. Dalam Yohanes 15: 14-15 Dia berkata, "Kamu adalah sahabat-sahabat-Ku, jikalau kamu berbuat apa yang Kuperintahkan kepadamu. Aku tidak lagi menyebut kamu hamba, sebab hamba tidak tahu apa yang diperbuat oleh tuannya, tetapi Aku menyebut kamu sahabat, karena Aku telah memberitahukan kepada kamu segala sesuatu yang telah Kudengar dari Bapa-Ku." Dia memperluas persahabatan kepada semua orang yang menunjukkan kasih pemberian Allah, kasih yang mengorbankan dari orang lain. Kasih itu memberikan keteguhan hati ketika ketakutan datang. Hanya ketika mengasihi Tuhan, dapat dengan penuh iman memberi makan domba-domba. ${ }^{5}$

Gembala terkait dengan doa. Doa merupakan bagian signifikan dari kehidupan Kristus. Dalam kehidupan doa-Nya, Dia memberikan teladan ketundukan. Dalam Lukas 22:42 Yesus berdoa, "Ya Bapa-Ku, jikalau Engkau mau, ambillah cawan ini dari pada-Ku; tetapi bukan kehendak-Ku, melainkan kehendak-Mulah yang terjadi." Dalam doa ini Tuhan Yesus mengajarkan kepada umatNya tentang keterbukaan dan ketundukan dalam doa. Gembala sidang tidak perlu menyembunyikan keinginan pribadinya dari Allah, namun mengungkapkannya dalam hubungan pribadi (Yoh. 10:1-10).

Tugas pertama dari seorang gembala adalah memberi makan, karena makan adalah merupakan kebutuhan utama. Dalam Mazmur 23, tugas gembala adalah membawa domba ke padang rumput hijau. Dalam bahasa Yunani untuk kata kerja mengembalakan dipakai

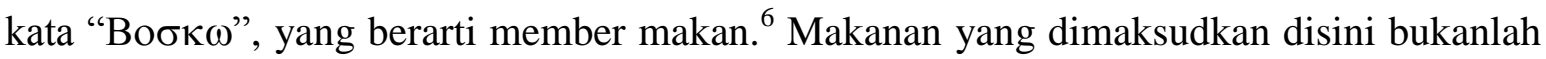
mengacu pada makanan fisik, tetapi pada makanan Rohani. Allah menginginkan agar gembala-gembalanya memberikan makanan yang baik bagi domba-domba yang digembalakannya.Kita harus menggali firman dengan sebaik-baiknya, mengerahkan daya upaya kita agar menemukan intisari yang paling baik dari setiap firman yang kita gali. ${ }^{7}$

Selain memberi makan, seorang gembala bertanggung jawab penuh untuk mengajar jemaatnya agar dapat hidup sesuai dengan kebenaran Firman Allah. Mengajar di sini adalah memberitahukan apa yang harus dilakukan jemaat dalam kehidupan sehari-hari,

\footnotetext{
${ }^{4}$ Arthur W. Pink, Exposition of the Gospel of Jhon (Grand Rapid, Mich: Zondervan, 1945),387. Dikutip dari buku yang ditulis oleh Jerry C. Wofford, Kepemimpinan Kristen yang Mengubahkan, hal. 133.

${ }^{5}$ Jerry C. Wofford. Hal.134.

${ }^{6}$ Newman M. Berclay, Kamus Yunani Indonesia (Jakarta:Gunung Mulia,1991),46

${ }^{7} \mathrm{http}: / /$ garamidunia.wordpress.com/2012/01/31/profil-gembala/
} 
memberikan pemahaman yang jelas akan ajaran-ajaran yang sesuai dengan kebenaran Firman Allah. Doni S. Basri mengatakan bahwa:"Seorang gembala harus mengajarkan atau memberitakan kebenaran-kebenaran yang sesuai Firman Allah.Memberiakn pemahaman pada jemaat untuk hidup berpatokan pada Firman Allah sebagai pusat anugerah Allah yang mampu menghapus dosa manusia melalui kematian di atas kayu salib."8

Dalam penggembalaan, gembala bertugas sebagai pemelihara jiwa-jiwa. Di sini letak perbedaan pelayanan penginjilan dan penggembalaan. Penginjilan adalah pemberitaan tentang keselamatan dan hasilnya adalah jiwa-jiwa baru.Selanjutnya jiwa-jiwa baru ini perlu dipelihara dalam penggembalaan. Para penginjil menyadari fungsi penggembalaan yang sedemikian. Sebagaimana Billy Graham berkata dalam bukunya Beritakanlah Injil tentang pengakuan para penginjil yaitu: "Kita bertanggung jawab untuk memelihara kerohanian orang-orang yang menerima Yesus melalui pelayanan kita, kita bertanggung jawab untuk mengajarkan, agar mereka menggabungkan diri dengan gereja setempat."9 John E. Ingouf berkata: Gembala yang baik memperhatikan keperluan kawanan dombanya. Anggota gereja mempunyai aneka ragam keperluan dan persoalan."10

Satu tugas gembala yang tidak terabaikan adalah sebagai penjaga. Gembala harus menjaga domba-domba dari gangguan dan bahaya yang mengancam. Gembala-gembala dalam perjanjian Lama menunjukkan kemampuannya untuk menjaga kawanan domba. Tugas gembala dalam perjanjian Baru tidak berbeda dengan Perjanjian Lama yakni menjaga keselamatan kawanan domba. Mengenai tugas gembala sebagai penjaga, Charles Jefferson mengatakan:'Pertama-tama seorang gembala dari Timur adalah penjaga.Sifat waspada merupakan suatu sifat yang penting baginya. Ada berbagai jenis musuh, semuanya berbahaya, masing-masing berbeda sifat bahayanya. ${ }^{11}$

\section{METODE PENELITIAN}

Metode penelitian yang digunakan dalam penelitian ini adalah metode kualitatif artinya data yang dikumpulkan bukan berupa angka-angka, melainkan data tersebut berasal dari naskah wawancara, catatan lapangan, dokumen pribadi, catatan, memo, dan dokumen resmi lainnya. Sehingga, yang menjadi tujuan dari penelitian kualitatif ini adalah ingin menggambarkan realita empirik di balik fenomena secara mendalam, rinci dan tuntas. Oleh karena itu penggunaan pendekatan kualitatif dalam penelitian ini adalah dengan mencocokkan antara realita empirik dengan teori yang berlaku dengan menggunakan metode diskriptif. Objek dijadikan responden dalam penelitian ini adalah 10 gembala, tepatnya di GPdI Wilayah XIII se-Kabupaten Lumanjang.

\footnotetext{
${ }^{8}$ Doni S. Basri, Diktat Dasar-dasar Penggembalaan, (Surabaya: Sekolah Teologia Tertulis, 1998) 53

${ }^{9}$ Billy Graham, Beritakan Injil (Bandung:Lembaga Literatur Baptis,1992), 144

${ }^{10}$ John E. Ingouf, Sekelumit tentang Gembala Sidang(Bandung:Lembaga Literatur Baptis, 1988), 39

${ }^{11}$ Charles Jefferson, Pejabat Gereja sebagai gembala Sidang (Mimery Press, 1977), 41
} 
Tabel 1: Kisi-kisi Instrumen Efektivitas Pelayanan Gembala Sidang

\begin{tabular}{|c|c|c|c|}
\hline Variabel & Indikator & Sub-Indikator & Item Pernyataan \\
\hline \multirow{9}{*}{$\begin{array}{l}\text { Efektivitas } \\
\text { Pelayanan } \\
\text { Gembala }\end{array}$} & \multirow[t]{3}{*}{$\begin{array}{l}\text { Pelayanan } \\
\text { Pribadi } \\
\text { Gembala. }\end{array}$} & Melayani dengan kasih & $\begin{array}{l}\text { Apakah saudara melayani jemaat } \\
\text { dengan kasih sehingga pelayanan } \\
\text { semakin berkembang? }\end{array}$ \\
\hline & & $\begin{array}{l}\text { Memiliki hubungan persahabatan } \\
\text { dengan jemaat }\end{array}$ & $\begin{array}{l}\text { Apakah saudara membangun hubungan } \\
\text { persaudaraan dengan jemaat? }\end{array}$ \\
\hline & & $\begin{array}{l}\text { Memiliki kehidupan pelayanan } \\
\text { doa yang sehat }\end{array}$ & $\begin{array}{l}\text { Apakah saudara melayani jemaat } \\
\text { dengan doa pribadi? }\end{array}$ \\
\hline & \multirow{3}{*}{$\begin{array}{l}\text { Efektivitas } \\
\text { Gembala Jemaat } \\
\text { dalam } \\
\text { Penggembalaan } \\
\text { Gere }\end{array}$} & $\begin{array}{l}\text { Memberi Pelayanan Firman } \\
\text { Tuhan secara teratur }\end{array}$ & $\begin{array}{l}\text { Apakah saudara member pelayanan } \\
\text { Firman Tuhan secara teratur? }\end{array}$ \\
\hline & & Memelihara jiwa jemaat. & $\begin{array}{l}\text { Apakah saudara memelihara jiwa } \\
\text { jemaat? }\end{array}$ \\
\hline & & $\begin{array}{l}\text { Menjaga jemaat dari pengaruh } \\
\text { ajaran sesat }\end{array}$ & $\begin{array}{l}\text { Bagaimana saudara menjaga jemaat } \\
\text { dari pengaruh ajaran sesat? }\end{array}$ \\
\hline & \multirow{3}{*}{$\begin{array}{l}\text { Efektivitas } \\
\text { Pelayanan } \\
\text { Penjangkauan }\end{array}$} & Mengadakan Penginjilan & Apakah saudara menginjil? \\
\hline & & Memuridkan & Apakah saudara memuridkan jemaat? \\
\hline & & Merintis Ladang Baru & Apakah saudara merintis ladang baru? \\
\hline
\end{tabular}

Tabel 2: Kisi-kisi instrumen Pertumbuhan Gereja

\begin{tabular}{|c|c|c|c|}
\hline Variabel & Indikator & Sub Idikator & Item Pertanyaan \\
\hline \multirow{8}{*}{$\begin{array}{l}\text { Pertumbuhan } \\
\text { Gereja }\end{array}$} & \multirow{3}{*}{$\begin{array}{l}\text { Pertumbuhan } \\
\text { Kuantitatif }\end{array}$} & Pertumbuhan Biologis & $\begin{array}{l}\text { Apakah ada pertumbuhan secara biologis } \\
\text { di gereja saudara? }\end{array}$ \\
\hline & & $\begin{array}{l}\text { Pertumbuhan karena } \\
\text { perpindahan. }\end{array}$ & $\begin{array}{l}\text { Apakah ada pertumbuhan karena } \\
\text { perpindahan jemaat digereja saudara? }\end{array}$ \\
\hline & & $\begin{array}{l}\text { Pertumbuhan dari pemulihan } \\
\text { hidup. }\end{array}$ & $\begin{array}{l}\text { Apakah ada pertumbuhan karena } \\
\text { pemulihan hidup di gereja saudara? }\end{array}$ \\
\hline & \multirow{5}{*}{$\begin{array}{l}\text { Pertumbuhan } \\
\text { secara } \\
\text { kualitatif }\end{array}$} & Pertumbuhan dari penginjilan & $\begin{array}{l}\text { Apakah ada pertumbuhan dari hasil } \\
\text { penginjilan? }\end{array}$ \\
\hline & & $\begin{array}{l}\text { Jemaat Tekun Belajar Firman } \\
\text { Tuhan }\end{array}$ & $\begin{array}{l}\text { Apakah jemaat di tempat saudara tekun } \\
\text { belajar Firman Tuhan? }\end{array}$ \\
\hline & & Jemaat tekun dalam doa & Apakah jemaat tekun dalam doa? \\
\hline & & Jemaat suka memberi & Apakah jemaat sudara suka member? \\
\hline & & $\begin{array}{l}\text { Jemaat memiliki persekutuan } \\
\text { yang sehat sesame jemaat }\end{array}$ & $\begin{array}{l}\text { Apakah jemaat memiliki persekutuan yang } \\
\text { sehat dengan sesame anggota jemaat? }\end{array}$ \\
\hline
\end{tabular}

\section{Deskripsi Data}

Cara yang digunakan dalam mengatur dan menyajikan diskripsi dalam penelitian ini adalah dengan Efect Rashoman, yaitu dengan mendiskripsikan data, dilihat dari beberapa versi sudut pandang beberapa orang. ${ }^{12}$ Diskripsi dalam penelitian ini menjadi usaha untuk mendapat jawaban tentang bagaimana efektivitas pelayanan gembala jemaat terhadap pertumbuhan gereja di lingkungan GPdI se-Kabupaten Lumajang. Wawancara dilakukan

\footnotetext{
12 Ibid., 115.
} 
oleh peneliti kepada 10 partisipan yaitu Gembala Jemaat Mandiri di Lingkungan GPdI se Kabupaten lumajang. Untuk memahami lebih lanjut mengenai hal tersebut di atas, maka secara berurutan hasil wawancara dan akan didiskripsikan dalam 17 pokok utama dalam bentuk pertanyaan sesuai variabelnya masing-masing yaitu:

I. Efektivitas Pelayanan Pribadi Gembala jemaat Mandiri, terdiri dari:

a. Melayani berdasarkan kasih.

b. Memiliki hubungan persahabatan dengan jemaat

c. Memiliki kehidupan pelayanan doa yang sehat

II. Efektivitas Gembala Jemaat dalam Penggembalaan Gereja terdiri dari:

a. Memberi Pelayanan Firman Tuhan secara teratur

b. Memelihara jiwa jemaat.

c. Menjaga jemaat dari pengaruh ajaran sesat

III. Efektivitas Pelayanan Penjangkauan terdiri dari:

a. Mengadakan Penginjilan

b. Memuridkan.

c. Merintis Ladang Baru.

IV. Pertumbuhan Gereja secara Kuantitatif terdiri dari:

a. Pertumbuhan secara biologis

b. Pertumbuhan karena perpindahan.

c. Pertumbuhan dari pemulihan hidup.

d. Pertumbuhan dari penginjilan.

V. Pertumbuhan secara Kualitas terdiri dari:

a. Jemaat Tekun Belajar Firman Tuhan

b. Jemaat tekun dalam doa

c. Jemaat suka memberi.

d. Jemaat memiliki persekutuan yang sehat sesama jemaat.

Tabel 3: Melayani Berdasarkan Kasih

\begin{tabular}{|l|c|c|}
\hline Jawaban Partisipan & Jumlah & Prosentase \\
\hline $\begin{array}{l}\text { Pelayanan yang disertai dengan pengorbanan sebab jiwa-jiwa adalah milik } \\
\text { Tuhan }\end{array}$ & 8 & $80 \%$ \\
\hline Memberi beras kepada tetangga di sekitar gereja & 1 & $10 \%$ \\
\hline Membantu jemaat yang miskin dan mereka semakin tekun ibadah & 1 & $10 \%$ \\
\hline jumlah & 10 & $100 \%$ \\
\hline
\end{tabular}

\section{Tabel 4: Memiliki Hubungan Persahabatan dengan Jemaat}

\begin{tabular}{|l|c|c|}
\hline Jawaban Partisipan & Jumlah & Prosentase \\
\hline $\begin{array}{l}\text { Gembala sebagai sahabat Tuhan, sehingga jemaat dapat menyampaikan keluh } \\
\text { kesah mereka kepada gembala dengan kepercayaan tanpa rasa takut atau malu. }\end{array}$ & 7 & $70 \%$ \\
\hline $\begin{array}{l}\text { Sebagai pemimpin saya jadikan jemaat itu patner atau mitra kerja yang saling } \\
\text { membutuhkan. }\end{array}$ & 2 & $20 \%$ \\
\hline \begin{tabular}{l|c|} 
Menganggap jemaat sebagai keluarga yang paling akrab bagi kami bagi gembala \\
Jumlah
\end{tabular} & 10 & $10 \%$ \\
\hline
\end{tabular}


Tabel 5: Memiliki Kehidupan Pelayanan Doa yang Sehat

\begin{tabular}{|l|c|c|}
\hline Jawaban Partisipan & Jumlah & Prosentase \\
\hline $\begin{array}{l}\text { Mempengaruhi pelayanan yang tujuannya dalam doa pribadi gembala, selalu } \\
\text { berdoa untuk kebutuhan jemaat menyebutkan nama-nama dan persoalan yang } \\
\text { dihadapi jemaat. }\end{array}$ & 8 & $80 \%$ \\
\hline $\begin{array}{l}\text { Berdoa pribadi untuk jemaat sangat penting karena berdampak pada } \\
\text { pertumbuhan iman jemaat. }\end{array}$ & 1 & $10 \%$ \\
\hline $\begin{array}{l}\text { Doa pribadi dengan membuat menara doa, dan membuat catatan/daftar } \\
\text { pergumulan jemaat. }\end{array}$ & 1 & $10 \%$ \\
\hline Jumlah & 10 & $100 \%$ \\
\hline
\end{tabular}

\section{Tabel 6: Memberi Pelayanan Firman Tuhan Secara Teratur}

\begin{tabular}{|l|l|l|}
\hline Jawaban Partisipan & Jumlah & Prosentase \\
\hline $\begin{array}{l}\text { Pelayanan Firman Tuhan harus sampaikan secara teratur melalui pendalam } \\
\text { Alkitab dan Firman Tuhan juga disheringkan kepada jemaat. Pelayanan ini } \\
\text { lebih efektif bagi pertumbuhan rohani jemaat. }\end{array}$ & 8 & $80 \%$ \\
\hline $\begin{array}{l}\text { Belum semua dilakukan secara teratur, hanya pada waktu berkhotbah } \\
\text { disesuaikan dengan kebutuhan jemaat dan dilakukan waktu ibadah hari } \\
\text { minggu saja }\end{array}$ & 2 & $20 \%$ \\
\hline Jumlah & 10 & $100 \%$ \\
\hline
\end{tabular}

\section{Tabel 7: Memelihara jiwa Jemaat}

\begin{tabular}{|l|c|c|}
\hline Jawaban Partisipan & Jumlah & Prosentasi \\
\hline $\begin{array}{l}\text { Memberikan perhatian kepada jemaat dengan mengadakan kunjungan yang } \\
\text { tujuannya memberikan jawaban atas masalah-masalah yang mereka hadapi } \\
\text { berdasarkan Firman Tuhan }\end{array}$ & 9 & $90 \%$ \\
\hline $\begin{array}{l}\text { Memberi makan Firman dengan urapan Roh Kudus, supaya mereka semakin } \\
\text { setia melakukan Firman Tuhan. }\end{array}$ & 1 & $10 \%$ \\
\hline Jumlah & 10 & $100 \%$ \\
\hline
\end{tabular}

\section{Tabel 8: Menjaga Jemaat dari Pengaruh Ajaran Sesat}

\begin{tabular}{|l|l|l|}
\hline Jawaban Partisipan & Jumlah & Prosentase \\
\hline $\begin{array}{l}\text { Selalu mengingatkan supaya waspada terhadap ajaran sesat dan perlu } \\
\text { menanamkan dan mengajar jemaat dengan pengetahuan Firman Allah supaya } \\
\text { mereka tidak terpengaruh ajaran sesat. }\end{array}$ & 9 & $90 \%$ \\
\hline Dengan memberikan doktrin yang berdasarkan Firman Tuhan yang murni. & 1 & $10 \%$ \\
\hline Jumlah & 10 & $100 \%$ \\
\hline
\end{tabular}

Tabel 9: Mengadakan Penginjilan yang Sering Dilakukan

\begin{tabular}{|l|c|c|}
\hline Jawaban Partisipan & Jumlah & Prosentase \\
\hline $\begin{array}{l}\text { Melakukan penginjilan pribadi kepada orang yang belum percaya secara pribadi } \\
\text { dengan lebih dahulu membangun hubungan yang baik. }\end{array}$ & 6 & $60 \%$ \\
\hline Penginjilan melalui perkataan dan perbuatan nyata. & 2 & $20 \%$ \\
\hline Mendorong jemaat menjadi saksi bagi orang lain. & 2 & $20 \%$ \\
\hline Jumlah & 10 & $100 \%$ \\
\hline
\end{tabular}


Tabel 10: Melakukan Pemuridan

\begin{tabular}{|l|c|c|}
\hline Jawaban Partisipan & Jumlah & Prosentase \\
\hline $\begin{array}{l}\text { Mengajar dan mendidik jemaat dengan Firman Tuhan dan menjadikan jemaat } \\
\text { saksi seperti dalam amanat agung Tuhan Yesus. }\end{array}$ & 7 & $70 \%$ \\
\hline $\begin{array}{l}\text { Memberikan kepercayaan kepada jemaat untuk terlibat aktif dalam segala } \\
\text { pelayanan di gereja. }\end{array}$ & 2 & $20 \%$ \\
\hline Menjadi saksi Kristus bagi keluarganya sendiri. & 1 & $10 \%$ \\
\hline Jumlah & 10 & $100 \%$ \\
\hline
\end{tabular}

\section{Tabel 11: Merintis Ladang Baru}

\begin{tabular}{|l|c|c|}
\hline Jawaban Partisipan & Jumlah & Prosentase \\
\hline $\begin{array}{l}\text { Dengan cara memanfaatkan rumah jemaat untuk diadakan persekutuan yang } \\
\text { kemudian berkembang menjadi gereja. }\end{array}$ & 8 & $80 \%$ \\
\hline Dengan mebuka cabang pos PI & 2 & $20 \%$ \\
\hline Jumlah & 10 & $100 \%$ \\
\hline
\end{tabular}

\section{Tabel 12: Pertumbuhan Secara Biologis}

\begin{tabular}{|l|c|c|}
\hline Jawaban Partisipan & Jumlah & Prosentase \\
\hline $\begin{array}{l}\text { Pasangan jemaat yang produktif dalam gereja akan menambah pertumbuhan } \\
\text { kuantitas, melalui kelahiran. }\end{array}$ & 7 & $70 \%$ \\
\hline Jumlah anak-anak sekolah minggu bertambah. & 2 & $20 \%$ \\
\hline Jumlah jemaat pemuda dan remaja bertambah dalam ibadah. & 1 & $10 \%$ \\
\hline Jumlah & 10 & $100 \%$ \\
\hline
\end{tabular}

\section{Tabel 13: Pertumbuhan Gereja karena Perpindahan}

\begin{tabular}{|l|c|c|}
\hline Jawaban Partisipan & Jumlah & Prosentase \\
\hline Bertambah karena pindah yang disebabkan tugas, pekerjaan dan pindah rumah & 7 & $70 \%$ \\
\hline Pertambahan jemaat karena pindah gereja & 2 & $20 \%$ \\
\hline Perpindahan karena orang tua ikut anaknya & 1 & $10 \%$ \\
\hline Jumlah & 10 & $100 \%$ \\
\hline
\end{tabular}

\section{Tabel 14: Pertumbuhan dari Pemulihan hidup (restorasi)}

\begin{tabular}{|l|c|c|}
\hline Jawaban Partisipan & Jumlah & Prosentase \\
\hline $\begin{array}{l}\text { Pelayanan oleh gembala jemaat yang lama tidak kegereja dibesuk sehingga } \\
\text { mengalami pertobatan dan aktif dalam pelayanan kembali. }\end{array}$ & 8 & $80 \%$ \\
\hline Dipulihkan melaui pelayanan kesaksian jemaat ke jemaat lain & 1 & $20 \%$ \\
\hline Dipulih dari ikatan roh perdukunan & 1 & $10 \%$ \\
\hline Jumlah & 10 & $100 \%$ \\
\hline
\end{tabular}

\section{Tabel 15: Pertumbuhan dari Penginjilan (konversi)}

\begin{tabular}{|l|c|c|}
\hline Jawaban Partisipan & Jumlah & Prosentase \\
\hline $\begin{array}{l}\text { Tugas saya gembala tidak dapat dipisahkan dari penginjilan yaitu menginjili } \\
\text { jiwa-jiwa yang belum mengenal Tuhan Yesus. }\end{array}$ & 8 & $80 \%$ \\
\hline Sebab satu jiwa sangat berharga dihadapan Tuhan untuk diselamatkan. & 1 & $10 \%$ \\
\hline Menginjil dan memenangkan jiwa 7 orang dalam waktu 1 tahun. & 1 & $10 \%$ \\
\hline Jumlah & 10 & $100 \%$ \\
\hline
\end{tabular}


Tabel 16: Jemaat Tekun Belajar Firman Tuhan

\begin{tabular}{|l|c|c|}
\hline Jawaban Partisipan & Jumlah & Prosentase \\
\hline $\begin{array}{l}\text { Dengan tekun belajar Firman Tuhan jemaat mengerti kehendak Allah dan } \\
\text { mereka menjadi pelaku-pelaku firman Tuhan. }\end{array}$ & 8 & $80 \%$ \\
\hline $\begin{array}{l}\text { Jemaat tekun belajar Firman Tuhan pada waktu pendalaman Alkitab di gereja, } \\
\text { melalui shering Alkitab. }\end{array}$ & 1 & $30 \%$ \\
\hline Belajar Firman Tuhan masih perlu ditingkatkan lagi & 1 & $10 \%$ \\
\hline Jumlah & 10 & $100 \%$ \\
\hline
\end{tabular}

\section{Tabel 17: Jemaat Tekun di dalam Doa}

\begin{tabular}{|l|c|c|}
\hline Jawaban Partisipan & Jumlah & Prosentase \\
\hline $\begin{array}{l}\text { Jemaat disarankan melakukan doa dan puasa setiap hari jumat dan doa pribadi } \\
\text { setiap hari }\end{array}$ & 9 & $90 \%$ \\
\hline Jemaat melakukan doa semalaman & 1 & $10 \%$ \\
\hline Jumlah & 10 & $100 \%$ \\
\hline
\end{tabular}

\section{Tabel 18: Jemaat Suka Memberi}

\begin{tabular}{|l|c|c|}
\hline Jawaban Partisipan & Jumlah & Prosentase \\
\hline $\begin{array}{l}\text { Jemaat memberi karena mereka mengerti dari Firman Tuhan bahwa mereka } \\
\text { melakukannya untuk Tuhan }\end{array}$ & 8 & $80 \%$ \\
\hline Memberi dalam bentuk kolekte dan persepuluhan kepada gembala & 1 & $10 \%$ \\
\hline Mereka memberi dalam bentuk aksi sosial seperti bencana alam. & 1 & $10 \%$ \\
\hline Jumlah & 10 & $100 \%$ \\
\hline
\end{tabular}

\section{Tabel 19: Jemaat Memiliki Persekutuan yang Sehat Sesama Jemaat}

\begin{tabular}{|l|c|c|}
\hline Jawaban Partisipan & Jumlah & Prosentase \\
\hline $\begin{array}{l}\text { Hidup saling mengasihi dan peduli terhadap jemaat yang sedang mengalami } \\
\text { masalah. }\end{array}$ & 6 & $60 \%$ \\
\hline Saling mengingatkan jika ada yang tidak beribadah. & 2 & $20 \%$ \\
\hline Saling mengunjungi jika ada jemaat yang sakit. & 2 & $20 \%$ \\
\hline Jumlah & 10 & $100 \%$ \\
\hline
\end{tabular}

\section{HASIL DAN PEMBAHASAN}

Setelah data diola dan didiskripsikan, maka langkah berikutnya adalah melakukan analisis data. Analisis adalah membahas identifikasi ciri-ciri objek serta menjelaskan secara sistematis hubungan diantara ciri-ciri itu dengan singkat dan bagaimana objek beroperasi. Dari segi tujuan yang ditetapkan, analisis dapat juga dipergunakan untuk membahas secara evaluatif pertanyaan mengapa sesuatu sistem tidak beroperasi atau bagaimana meningkatkan operasi sistem itu.

\section{Melayani Berdasarkan Kasih}

Ditinjau dari landasan teori, maka gembala jemaat mandiri di lingkungan GPdI di Lumajang ada dalam kategori sangat efaktif melakukan pelayanan dalam kasih. Pelayanan yang disertai dengan pengorbanan dan memahami bahwa jiwa-jiwa adalah milik Tuhan 
yang harus digembalakan dengan kasih, seperti Yesus adalah Gembala yang baik dan penuh kasih.

\section{Memiliki Hubungan Persahabatan dengan Jemaat}

Dalam landasar teori hubungan persahabatan dengan jemaat adalah seperti Tuhan Yesus telah menyatakan persahabatan dengan para pengikut-Nya. Dalam Yohanes 15: 1415 Dia berkata, "Kamu adalah sahabat-sahabat-Ku, jikalau kamu berbuat apa yang Kuperintahkan kepadamu. Aku tidak lagi menyebut kamu hamba, sebab hamba tidak tahu apa yang diperbuat oleh tuannya, tetapi Aku menyebut kamu sahabat, karena Aku telah memberitahukan kepada kamu segala sesuatu yang telah Kudengar dari Bapa-Ku." Dia memperluas persahabatan kepada semua orang yang menunjukkan kasih pemberian Allah, kasih yang mengorbankan diri kepada orang lain.

\section{Memiliki Kehidupan Pelayanan Doa yang Sehat}

Sebanyak $80 \%$ partisipan, memiliki kehidupan pelayanan doa yang sehat memengaruhi pelayanan yang tujuannya dalam doa pribadi gembala, selalu berdoa untuk kebutuhan jemaat menyebutkan nama-nama dan persoalan yang dihadapi jemaat.

\section{Memberi Firman Tuhan secara Teratur}

Sebanyak 80\% dari 10 partisipan menjawab Pelayanan Firman Tuhan harus sampaikan secara teratur melalui pendalam Alkitab dan Firman Tuhan juga dibagikan kepada jemaat. Pelayanan ini lebih efektif bagi pertumbuhan rohani jemaat.

\section{Memelihara Jiwa Jemaat}

90\% partisipan menjawab bahwa dalam tugas penggembalaan gembala jemaat mandiri dengan memberikan perhatian kepada jemaat dengan mengadakan kunjungan, tujuannya memberikan jawaban atas masalah-masalah yang mereka hadapi berdasarkan Firman Tuhan.

\section{Menjaga Jemaat dari Pengaruh Ajaran Sesat}

90\% partisipan menjawab Selalu mengingatkan supaya waspada terhadap ajaran sesat dan perlu menanamkan dan mengajar jemaat dengan pengetahuan Firman Allah supaya mereka tidak terpengaruh ajaran sesat.

\section{Mengadakan Penginjilan}

Sebanyak $60 \%$ partisipan mengadakan penginjilan melakukan penginjilan pribadi kepada orang yang belum percaya secara pribadi dengan lebih dahulu membangun hubungan yang baik . sedangkan 40\% masing-masing partisiapan $20 \%$ menjawab bahwa Penginjilan melalui perkataan dan perbuatan nyata. Dan $20 \%$ lagi partisipan menjawab dengan mendorong jemaat menjadi saksi bagi orang lain. 


\section{Melakukan Pemuridan}

Diketahui bahwa $70 \%$ dari 10 partisipan pelayanan gembala jemaat mandiri di lingkungan GPdI se Kabupaten Lumajang melaukan pelayanan pemuridan adalah Mengajar dan mendidik jemaat dengan Firman Tuhan dan menjadikan jemaat saksi seperti dalam amanat agung Tuhan Yesus.

\section{Merintis Ladang Baru}

$80 \%$ partisipan sudah melakukan pelayanan perintisan. Hal itu disebabkan bahwa gembala jemaat mandiri menyadari bahwa melakukan perintisan ladang baru merupakan hal yang penting yang harus dilakukan dalam tugas pelayanan penjangkauan.

\section{Pertumbuhan Gereja secara Kuantitatif}

\section{Pertumbuhan Secara Biologis}

$70 \%$ partisipan menjawab bahwa Pasangan jemaat yang produktif dalam gereja akan menambah pertumbuhan kuantitas, melalui kelahiran. Hal ini disebabkan oleh karena pasangan suami istri yang telah menikah sebagian besar pasti akan melahirkan, dan hanya $20 \%$ partisipan yang menjawab jumlah anak sekolah minggu bertambah oleh karena angka kelahiran itu dan anak bertumbuh.

\section{Pertumbuhan karena Perpindahan}

$70 \%$ dari 10 partisipan menjawab Bertambah karena ada yang perpindahan disebabkan tugas, pekerjaan dan pindah rumah dan $20 \%$ partisipan menjawab bahwa pertambahan jemaat karena pindah gereja kemudian $10 \%$ partisipan menjawab bahwa pindah karena orang tua ikut tinggal dengan anaknya.

\section{Pertumbuhan dari Pemulihan Hidup Restorasi}

80\% partisipan mengalami pertumbuhan jemaat karena Pelayanan gembala kepada jemaat yang lama tidak kegereja, sehingga mengalami pertobatan dan aktif dalam pelayanan kembali di tempat pelayanan.

\section{Pertumbuhan Melalui Penginjilan}

$80 \%$ partisipan menjawab tugas gembala tidak dapat dipisahkan dari penginjilan yaitu menginjili jiwa-jiwa yang belum mengenal Tuhan Yesus. Dan pertumbuhan pertobatan adalah orang-orang bukan kristen yang telah menerima dan menjadi murid Kristus .

\section{Pertumbuhan secara Kualitas}

\section{Jemaat Tekun Belajar Firman Tuhan}

80\% partisipan menjawab Dengan tekun belajar Firman Tuhan jemaat mengerti kehendak Allah dan mereka menjadi pelaku-pelaku firman Tuhan. Sedangkan masingmasing $10 \%$ partisipan menjawab Jemaat tekun belajar Firman Tuhan pada waktu pendalaman Alkitab di gereja. 


\section{Jemaat Tekun dalam Doa}

90\% partisipan menjawab jemaat disarankan melakukan doa dan puasa setiap hari jumat dan doa pribadi setiap hari. Gembala jemaat mandiri menyadari bahwa pelayanan dengan mengajar jemaat tekun di dalam doa merupakan langkah pertumbuhan kualitas bagi jemaat.

\section{Jemaat suka memberi.}

80\% partisipan menjawab Jemaat memberi karena mereka mengerti Firman Tuhan dan mereka melakukannya untuk Tuhan, sedangkan $20 \%$ partisipan menjawab memberi dalam bentuk kolekte dan persepuluhan dan juga melakukan aksi sosial.

\section{Jemaat Memiliki Persekutuan yang Sehat Sesama Jemaat}

$60 \%$ partisipan menjawab Hidup saling mengasihi dan peduli terhadap jemaat yang sedang mengalami masalah. Sedangkan $20 \%$ partisipan menjawab Saling mengingatkan jika ada yang tidak beribadah. 20\% partisipan menjawab Saling mengunjungi jika ada jemaat yang sakit.

\section{KESIMPULAN}

Dengan berorientasi pada tujuan penelitian, deskripsi, analisis data dan interpretasi yang telah dijelaskan sebelumnya, maka berikut ini akan disimpulkan hasil penelitian Peranan Efektivitas Gembala Jemaat Terhadap pertumbuhan Gereja di Lingkungan GPdI Se-Kabupaten Lumajang Jawa Timur tentang Efektivitas Pelayanan Gembala dan Implementasinya dalam terhadap pertumbuhan gereja. Kesimpulan akhir dari yang dapat ditarik dari penelitian ini adalah gembala jemaat mandiri di lingkungan GPdI se Kabupaten Lumajang, sebagian besar dampak dari peranan efaktivitas pelayanan gembala jemaat mandiri terhadap pertumbuhan gereja sesuai dengan landasan teori dan selalu melakukannya dalam pelayanan.

\section{REFERENSI}

Alkitab Edisi Studi, Jakarta: Lembaga Alkitab Indonesia, 1988

Arthur W. Pink, Exposition of the Gospel of Jhon ,Grand Rapid, Mich: Zondervan, 1945. DikutipBilly Graham, Beritakan Injil ,Bandung:Lembaga Literatur Baptis,1992.

Charles Jefferson, Pejabat Gereja sebagai gembala Sidang, Mimery Press, 1977.

Doni S. Basri, Diktat Dasar-dasar Penggembalaan, Surabaya: Sekolah Teologia Tertulis, 1998.

Dwiraharjo, Susanto. "Kajian Eksegetikal Amanat Agung Menurut Matius 28 : 18-20." Jurnal Teologi Gracia Deo 1, no. 2 (2019): 56-73. http://sttbaptisjkt.ac.id/ejournal/index.php/graciadeo.

Jerry C. Worfford, Kepemimpinan Kristen yang Mengubahkan, Yogyakarta: Yayasan ANDI, 1999dari buku yang ditulis oleh Jerry C. Wofford, Kepemimpinan Kristen yang Mengubahkan, 
John E. Ingouf, Sekelumit tentang Gembala Sidang(Bandung:Lembaga Literatur Baptis, 1988),39

Newman M. Berclay, Kamus Yunani Indonesia (Jakarta:Gunung Mulia,1991),46

L. Anthony, Pelayanan Pastoral (Yokyakarta: STII, Diktat), 21

Prince Derek, Membangun Jemaat Kristus, Jakarta:YPI Imanuel,1995

Yefta Bonar Nainggolan, Dampak Kemajuan Tehnologi dalam Pertumbuhan Gereja (Jember:STAJ,1996),77

http://garamidunia.wordpress.com/2012/01/31/profil-gembala/. 